\title{
DIREITOS DA PERSONALIDADE SOB A PERSPECTIVA DO DIREITO DO TRABALHO
}

\section{PERSONALITY RIGHTS UNDER LABOUR LAW PERSPECTIVE}

\author{
${ }^{1}$ Leiliane Piovesani Vidaletti \\ ${ }^{2}$ Ana Carolina Garcia Bonotto
}

\section{RESUMO}

A presente pesquisa visa ao estudo dos direitos fundamentais da personalidade nas relações do trabalho, notadamente no que se refere à suficiência e adequação da sua proteção. Com efeito, em face da inarredável lacuna do direito laboral quanto ao particular, amparando-se em disposição expressa celetista, busca-se no regramento civil a salvaguarda desses direitos. Todavia, diante das peculiaridades de que se revestem as demandas trabalhistas, inevitável se faz o debate e a reflexão quanto à pertinência da proteção dos direitos da personalidade do empregado, tema que se pretende explorar nesta pesquisa.

Palavras-Chave: Direitos da personalidade. Trabalhador. Jurisprudência trabalhista. Relações do trabalho. Direitos fundamentais.

\begin{abstract}
The present research aims to study the fundamental rights of personality within the labour relations, notedly in which regards the sufficiency and adequation of it protection. In effect, face the inarrrible gap of the labour laws as to the individual, propping up in express provision in the consolidation of labor laws, is sought in the civil law the safeguard of this rights. However, face the peculiaritis of which are coated the labor demands, inevitable is the debate and refletion about the pertinence of the protection of personality rights of the employee, theme that pretend to explore in this research.
\end{abstract}

Keywords: Rights of the personality. Worker. Labour law. Labour relations. Fundamental rights.

\footnotetext{
${ }^{1}$ Mestranda em Direito pela Pontifícia Universidade Católica do Rio Grande do Sul (PUCRS), Porto Alegre, Rio Grande do Sul, Brasil. Bolsista pela Coordenação de Aperfeiçoamento de Pessoal de Nível Superior (CAPES). Email: leilividaletti@yahoo.com.br ${ }^{2}$ Mestranda em Direito pela Pontifícia Universidade Católica do Rio Grande do Sul (PUCRS), Porto Alegre, Rio Grande do Sul, Brasil. Bolsista pela Coordenação de Aperfeiçoamento de Pessoal de Nível Superior (CAPES). Email: anabonotto@gmail.com
} 


\section{INTRODUÇÃO}

Os direitos da personalidade, entendidos como direitos subjetivos ligados à realização de valores existenciais do ser humano, tais como a vida, integridade física e psíquica, honra, intelectualidade, dentre outros decorrentes da dignidade da pessoa humana, conquanto tenham, conforme alguns autores, origem no século XVI, ainda suscitam fortes e acaloradas discussões em dias atuais, relativamente aos seus contornos, abrangências e limitações, em diversos ramos do direito, dentre os quais o do Trabalho, objeto desta pesquisa.

É bem verdade que a depender dos sabores do momento histórico, os direitos da personalidade podem receber proteção distinta, mais ou menos intensa, com alguns contornos cambiantes, como sói ocorrer com o direito à privacidade, inicialmente desenvolvido na doutrina norte-americana como o direito a estar só, vindo a ser conceitualmente ampliado e reinterpretado com a evolução dos costumes e, merecendo especial destaque, o desenvolvimento de novas tecnologias de comunicação e informação.

Todavia, não se descura da estreita ligação dos direitos da personalidade com a dignidade da pessoa humana e, ainda que se possam perceber diferentes nuanças em momentos históricos distintos, é sempre na linha de proteção deste valor supremo que se deve orientar a interpretação de tais direitos.

No que se refere aos direitos da personalidade do trabalhador, inexiste regramento específico na legislação trabalhista, fazendo-se uso, portanto, em esfera laboral, de forma subsidiária, da legislação civil. Contudo, não se pode olvidar que o Direito do Trabalho, como ramo autônomo do direito privado, possui características que lhes são próprias, restando evidente a necessidade de se perquirir se a legislação civilista atende de forma satisfatória às suas necessidades e anseios.

Para a análise do tema, far-se-á um breve passeio pela evolução histórica dos direitos da personalidade, seu conceito, natureza jurídica e características. Após, mediante a análise de alguns direitos da personalidade sob a perspectiva do Direito do Trabalho e de alguns julgados dos tribunais trabalhistas, verificar-se-á se os direitos fundamentais dos trabalhadores estão recebendo a proteção adequada.

Para tanto, far-se-á uso do método de abordagem hipotético-dedutivo, por meio do qual serão trazidas à lume hipóteses, formuladas na condição de respostas provisórias aos 
problemas apresentados, submetendo-as a rigoroso processo de verificação, de modo a falseálas, confirmando-as ou refutando-as.

Quanto à metodologia de procedimento, ampara-se, notadamente, nos métodos comparativo e monográfico. Trata-se, pois, de pesquisa teórica, a ser ancorada em pertinente e atualizada bibliografia, com cunho explicativo, pois focada nas consequências e relações entre os institutos abordados, mormente para fins de preservação dos direitos da personalidade na relação do trabalho.

\section{DIREITOS DA PERSONALIDADE}

Cumpre a este primeiro ponto abordar os direitos de personalidade a partir de uma análise da evolução histórica, com intuito de percorrer brevemente o reconhecimento do direito à honra no Direito Romano, o direito à imagem no Tribunal do Império Alemão, e o direito à privacidade na doutrina Estadunidense. Isto, visando demonstrar o desenvolvimento dos direitos da personalidade até que fosse possível alcançar uma alteração conceitual com a consequente inclusão destes direitos em legislações. Ademais, pretende-se adentrar no seu conceito, natureza jurídica e características a fim de analisar com que função surgem os direitos da personalidade no cenário jurídico e verificar as correntes que os fundamentam.

\subsection{Brevíssimo escorço histórico}

Já no Direito Romano, verifica-se uma preocupação com a defesa dos interesses relevantes da esfera pessoal, especialmente a honra. Todavia, embora haja doutrina em defesa da tese de que a Teoria dos Direitos da Personalidade remonte a autores do século XVI, como Donellus, certo é que somente ao final do século XIX foram melhor estabelecidos os contornos dos direitos da personalidade. (ANDRADE: 2013)

$\mathrm{Na}$ jurisprudência, destaca-se, dentre as primeiras decisões a respeito do tema, o famoso caso do Chanceler Bismarck, fotografado em seu leito de morte, no ano de 1898. Na oportunidade, os herdeiros do Chanceler processaram os fotógrafos e obtiveram, no Tribunal do Império Alemão, uma injunção para impedir a divulgação das imagens. Iniciava-se, aqui, a discussão acerca do direito à imagem.

Concomitantemente à decisão Europeia, na doutrina norte-americana defendia-se o direito à privacidade, inicialmente compreendido como o direito de estar só. Nessa linha, Danilo Doneda destaca que a doutrina do direito à privacidade, desenhada a partir do 
famigerado artigo de Samuel Warren e Louis Brandes - The right to privacy - marcava-se por nítido caráter individualista, calcada no direito de ser deixado só. Salienta, ainda, que o direito à privacidade, inserido em ordenamentos de cunho eminentemente patrimonialista, reservavase a extratos sociais bem determinados, o que veio a ser chamado pelo autor de "elitismo", modelo que durou até a década de 1960. (DONEDA: 2011)

Entretanto, a despeito do reconhecimento de alguns direitos da personalidade no final do século $\mathrm{XX}$, a sua dogmática ainda não se encontrava bem delineada, tampouco suficientemente difundida, a ponto de influenciar o Código Civil de Beviláqua, de 1916, que foi omisso quanto à matéria 3 .

Enquanto no direito privado o desenvolvimento da disciplina se dava de forma progressiva, mas ainda lenta, o direito público do século XX passava por uma extraordinária evolução, denominada por muitos doutrinadores de publicização do direito privado, com a inserção nas constituições de temas originariamente previstos no direito privado. Surge crescente interação entre direito público e direito privado, estabelecendo-se entre as duas áreas uma profunda dialética, que veio a influenciar, também, a Constituição brasileira de 1988.

Nessa linha, o Código Civil de 2002, alinhado com o espírito da Constituição de 1988, destinou um capítulo aos direitos da personalidade, demonstrando uma guinada no perfil da codificação que, sem descurar do caráter patrimonialista, marcadamente predominante no regramento de 1916, passou a se preocupar, essencialmente, com o indivíduo.

Evidentemente, a mudança paradigmática entre as codificações de 1916 e 2002 reflete a premente necessidade de avanço e adaptação da legislação infraconstitucional com a nova ordem imposta pela Constituição Federal de 1988, que erigiu a dignidade da pessoa humana ${ }^{4}$ a fundamento da República Federativa do Brasil $^{5}$ e valor supremo do ordenamento jurídico.

\footnotetext{
${ }^{3}$ Importa referir que o Código Civil de 1916 foi redigido por Beviláqua em 1899, ou seja, no final do séc. XIX, enquanto a dogmática dos direitos da personalidade não estava suficientemente difundida.

${ }^{4}$ Ingo Sarlet define a dignidade da pessoa humana como [...] qualidade intrínseca e distintiva de cada ser humano que o faz merecedor do mesmo respeito e consideração por parte do Estado e da comunidade, implicando, neste sentido, um complexo de direitos e deveres fundamentais que assegurem à pessoa tanto contra todo e qualquer ato de cunho degradante e desumano, como venham a lhe garantir as condições existenciais mínimas para uma vida saudável, além de propiciar e promover sua participação ativa e corresponsável nos destinos da própria existência e da vida em comunhão com os demais seres humanos. SARLET, Ingo Wolfgang. Dignidade da Pessoa Humana e Direitos Fundamentais. Porto Alegre: Livraria do Advogado, 2001.

${ }^{5}$ Artigo $1^{\circ}$ A República Federativa do Brasil, formada pela união indissolúvel dos Estados e Municípios e do Distrito Federal, constitui-se em Estado Democrático de Direito e tem como fundamentos:
} 
Nessa toada, a personalidade jurídica não se reduz à mera aptidão para ser sujeito de direitos e obrigações, mas vem dotada de direitos que visam à realização da dignidade da pessoa humana, enquanto valor máximo da ordem jurídica, a partir do qual devem ser interpretados e repensadas os institutos do direito privado.

Após esses esclarecimentos iniciais, é possível perceber porque o Código Civil de 1916, inspirado no Código de Napoleão, não tratava dos direitos da personalidade. Não havia campo fecundo para tal; foi preciso uma alteração conceitual que viabilizasse o reconhecimento dos direitos ligados à existência e consequente inclusão desses direitos nas legislações. No Brasil, essa inclusão ocorreu primeiro na Constituição de 1988 e, posteriormente, no Código Civil de 2002, momento em que já se encontrava suficientemente difundida pelo mundo a doutrina dos direitos da personalidade.

\subsection{Conceito, natureza jurídica e características}

Os direitos da personalidade surgem no cenário jurídico como mecanismos de defesa de valores inatos ao homem, como a vida, higidez física, intimidade, honra, intelectualidade, dentre outros direitos reconhecidos à pessoa humana, tomada em si mesma e em sua projeção com a sociedade (BITTAR: 2001).

Noutras palavras, podem ser conceituados como direitos subjetivos, que tem por objeto bens da personalidade que traduzem aspectos diretamente ligados ao ser humano: biológicos - vida, integridade física, saúde, necessidades vitais, etc; morais - integridade moral, identidade, nome, imagem, intimidade, etc; e sociais - família, bom nome, reputação, respeito... ${ }^{6}$

Vê-se, pois, que os direitos da personalidade se voltam à realização de valores existenciais, de caráter não patrimonial, ligados à dignidade da pessoa humana e que visam, em última análise, a concretização deste valor supremo no âmbito do direito civil. Nesse sentido, o enunciado 274 da Jornada de Direito Civil: Os direitos da personalidade, regulados de maneira não exaustiva pelo Código Civil, são expressões da cláusula geral de cautela da pessoa humana, contida no art. $1^{o}$, III, da Constituição Federal. ${ }^{7}$

III - a dignidade da pessoa humana;

${ }^{6}$ Nesse sentido, citando António Menezes Cordeiro, Jorge Miranda, Otávio Luiz Rodrigues Júnior e Gustavo Bonato Fruet, org. (MIRANDA, Jorge; RODRIGUES JUNIOR, Otávio Luiz; FRUET, Gustavo Bonato. Direitos da Personalidade. São Paulo: Atlas, 2012. P. 29).

${ }^{7}$ CRFB: Artigo $1^{\circ}$ A República Federativa do Brasil, formada pela união indissolúvel dos Estados e Municípios e do Distrito Federal, constitui-se em Estado Democrático de Direito e tem como fundamentos: 
Tormentosas discussões doutrinárias já foram travadas quanto à natureza dos direitos da personalidade. Na perspectiva de um direito civil patrimonial, havia dúvidas, inclusive, sobre a sua existência. Nesse sentido, no século XIX, Teixeira de Freitas repeliu a ideia de direitos da personalidade, ao argumento de que tais direitos não podiam ser traduzidos em valores pecuniários, em razão do que não seriam propriamente direitos. ${ }^{8}$

No mesmo sentido, consagrados autores, tais como Thon, Unger, Jellinek, Enecerus, Croome, Oertman, Von Thur, Ravà e Simoncelli negavam a existência de direitos da personalidade como direitos subjetivos, porquanto reconhecer o direito do homem sobre o homem, justificaria, em última análise, o suicídio. (BITTAR: 2001)

$\mathrm{Na}$ atualidade, todavia, não subsistem as polêmicas sobre a existência ou não dos direitos da personalidade, cingindo-se a celeuma, à sua natureza jurídica. Nesse particular, prevalece que os direitos da personalidade são poderes exercidos pelo homem sobre sua própria pessoa, ou seja, tais direitos têm por objeto as projeções físicas, psíquicas e morais do homem, considerado em si e em sociedade. (GAGLIANO: 2009)

Há de se mencionar, ainda, a existência de duas correntes distintas no que diz respeito ao fundamento jurídico de tais direitos.

Os primeiros, chamados positivistas, entendem que os direitos da personalidade, conquanto essenciais e inerentes ao homem, devem ser reconhecidos como tal pelo Estado, que lhes dá força jurídica. Para essa corrente, portanto, o direito de personalidade há de estar previsto, necessariamente, no ordenamento jurídico (TEPEDINO: 2001).

Em lado oposto, os naturalistas advogam que os direitos da personalidade prescindem de previsão legal, pois decorrem da tão-só condição de ser humano, correspondendo a faculdades exercitáveis normalmente pelo homem. Para Carlos Alberto Bittar (BITTAR: 2001), que adere a essa linha de pensamento, os direitos da personalidade são direitos inatos, cabendo ao Estado apenas reconhecê-los e sancioná-los no plano do direito positivo.

Em certos casos, prossegue o autor, os direitos da personalidade recebem consagração constitucional, ingressando no campo das liberdades públicas, amparados por um sistema de proteção próprio; noutros, são positivados em esfera infraconstitucional, como se constata no capítulo II do Código Civil de 2002; porém, em ambos os casos, não nasceram

$[\ldots]$

III - a dignidade da pessoa humana;

${ }^{8}$ Nesse sentido, citando Teixeira de Freitas, o autor Paulo Lobo (LOBO, Paulo. Direito Civil. Parte Geral. $4^{\mathrm{a}}$ ed. São Paulo: Saraiva, 2013. P. 129). 
com a inserção constitucional ou infraconstitucional, posto que já existissem, mas apenas passaram a contar com proteção mais específica e eficaz. (BITTAR: 2001)

Do conjunto das obras consultadas para a realização deste trabalho, constata-se que dentre as mais sensíveis características dos direitos da personalidade está a sua indisponibilidade ${ }^{9}$, ou seja, são direitos intransmissíveis, irrenunciáveis ${ }^{10}$ e inalienáveis, posto que possuem como objeto os bens mais elevados do homem, corolário de sua estreita ligação à dignidade da pessoa humana, valor tão caro à ordem jurídica pós-Constituição de 1988.

Não fora isso, não há como dissociar o homem de seus direitos da personalidade. É dizer, não se pode separar o homem de sua honra, intimidade ou imagem. São, portanto, direitos que pertencem à essência humana, dos quais o homem, ainda que hipoteticamente o quisesse, não se poderia desvincular, pois a ele pertencem pela tão-só condição de humanidade.

É preciso dizer, no entanto, que em casos específicos será possível ao titular ceder o exercício de alguns direitos da personalidade, tais como o direito à imagem ou os direitos autorais, sem despojar-se, porém, de sua titularidade. Trata-se de hipóteses excepcionais, específicas e limitadas, afinal a ninguém é dado dispor de forma geral e indefinida dos seus direitos da personalidade ${ }^{11}$.

Dentro desse caráter de excepcionalidade, ressalva-se que a previsão do artigo 13 do Código Civil ${ }^{12}$, que apregoa a impossibilidade de disposição do próprio corpo, quando importar diminuição permanente da integridade física ou contrariar os bons costumes, não elide a possibilidade de cirurgia de transgenitalização, conforme Resolução n. 1652/2002, do Conselho Federal de Medicina, situação que poderia se pautar na defesa da dignidade do transexual. No que se refere a transplantes, por sua vez, o artigo $9^{\circ}$ da Lei n. 9.434/97 $7^{13}$, alterado pela Lei n. 10.211/01, exige autorização judicial. Ainda, no contexto do artigo 13, o

\footnotetext{
9 Artigo 11 do Código Civil: Com exceção dos casos previstos em lei, os direitos da personalidade são intransmissíveis e irrenunciáveis, não podendo o seu exercício sofrer limitação voluntária.

${ }^{10}$ Conquanto intransmissíveis, não se descura da possibilidade de estabelecimento voluntário de restrições ao direito da personalidade. Nesse sentido, o enunciado n. 139 do Centro de Estudos Jurídicos da Justiça Federal: Artigo 11: Os direitos da personalidade podem sofrer limitações, ainda que não especificamente previstas em lei, não podendo ser exercidos com abuso de direito de seu titular, contrariamente à boa-fé objetiva e aos bons costumes.

${ }^{11}$ Vide teor do enunciado 4 da Jornada de Direito Civil: $O$ exercício dos direitos da personalidade pode sofrer limitação voluntária, desde que não seja permanente nem geral.

12 Artigo 13. Salvo por exigência médica, é defeso o ato de disposição do próprio corpo, quando importar diminuição permanente da integridade física, ou contrariar os bons costumes. Parágrafo único. $\mathrm{O}$ ato previsto neste artigo será admitido para fins de transplante, na forma estabelecida em lei especial.

${ }^{13}$ Art. 90 É permitida à pessoa juridicamente capaz dispor gratuitamente de tecidos, órgãos e partes do próprio corpo vivo, para fins terapêuticos ou para transplantes em cônjuge ou parentes consangüíneos até o quarto grau, inclusive, na forma do $\S 4^{\circ}$ deste artigo, ou em qualquer outra pessoa, mediante autorização judicial, dispensada esta em relação à medula óssea. $\quad$ (Redação dada pela Lei no 10.211, de 23.3.2001)
} 
artigo $4^{\mathrm{o}}$ da Lei de Transplantes ${ }^{14}$ exige autorização da família para que se implemente a doação de órgãos para depois da morte. Não obstante a posição que sustenta a incidência do artigo 14, do Código Civil ${ }^{15}$, homenageando a vontade da pessoa falecida, destaca Fábio Siebeneichler de Andrade, que a orientação prevalente é a de exigir a ratificação da família para que se viabilize a doação (ANDRADE: 2013).

Para além da mencionada indisponibilidade, os direitos da personalidade são absolutos, imprescritíveis, extrapatrimoniais, impenhoráveis e vitalícios.

São absolutos, porquanto oponíveis erga omnes. Imprescritíveis, pois não lhes é dado prazo para exercício, até mesmo porque considerados direitos inatos ou originários. De fundamental relevo, nesse momento, a advertência de que os efeitos patrimoniais decorrentes do dano moral se submetem a prazo prescricional, normalmente de três anos, consoante artigo 206, $\S 3^{\circ}$, V, do Código Civil ${ }^{16}$. Na mesma linha, impõe-se referir que a impenhorabilidade decorre diretamente da sua indisponibilidade, mas a mesma proteção não se estende à penhora do crédito decorrente de reparação pecuniária por lesão aos direitos morais do autor.

São, também, direitos extrapatrimoniais e vitalícios, pois são direitos insuscetíveis de valoração econômica, que acompanham o homem do seu nascimento até sua morte ${ }^{17}$.

Por fim, não se pode confundir o direito da personalidade com possível atribuição econômica decorrente de sua violação (reparação por danos morais). Além disso, o parágrafo único do artigo 12 do Código Civil não estabelece a transmissibilidade, com a morte, do direito da personalidade, mas a possibilidade de os legitimados nele previstos reclamarem, em nome próprio, a proteção dos direitos da personalidade do falecido, na condição de lesados indiretos.

\footnotetext{
${ }^{14}$ Art. 4o $\mathrm{A}$ retirada de tecidos, órgãos e partes do corpo de pessoas falecidas para transplantes ou outra finalidade terapêutica, dependerá da autorização do cônjuge ou parente, maior de idade, obedecida a linha sucessória, reta ou colateral, até o segundo grau inclusive, firmada em documento subscrito por duas testemunhas presentes à verificação da morte.

${ }^{15}$ Art. 14. É válida, com objetivo científico, ou altruístico, a disposição gratuita do próprio corpo, no todo ou em parte, para depois da morte.

Parágrafo único. $\mathrm{O}$ ato de disposição pode ser livremente revogado a qualquer tempo.

${ }^{16}$ Art. 206. Prescreve:

[...]

$\S 3$ Em três anos:

[...]

$\mathrm{V}$ - a pretensão de reparação civil;

${ }^{17}$ Artigo 12. Pode-se exigir que cesse a ameaça, ou a lesão, a direito da personalidade, e reclamar perdas e danos, sem prejuízo de outras sanções previstas em lei. Parágrafo único. Em se tratando de morto, terá legitimação para requerer a medida prevista neste artigo o cônjuge sobrevivente, ou qualquer parente em linha reta, ou colateral até o quarto grau.
} 
Após essa análise geral da evolução dos direitos da personalidade, de seu conceito, natureza jurídica e principais características, passa-se, a seguir, ao estudo de aspectos relacionados ao direito do trabalho.

\section{DIREITOS DA PERSONALIDADE E DIREITO DO TRABALHO}

Inicialmente, cumpre destacar que a Consolidação das Leis do Trabalho - CLT, Decreto-Lei 5.452 , de $1^{\circ}$ de maio de 1943 , não faz qualquer referência aos direitos da personalidade. Todavia, para salvaguarda desses direitos nas relações laborais, com fundamento no parágrafo único do artigo $8^{\circ 18}$, a CLT admite a aplicação subsidiária do direito comum, buscando-se, especialmente no direito civil, o suprimento de sua lacuna normativa.

Nas próximas linhas, far-se-á uma breve averiguação dos direitos à honra, imagem e uso do nome, bem como do direito à privacidade, sob a perspectiva da jurisprudência trabalhista. Salienta-se que não é objetivo deste trabalho realizar aprofundado estudo jurisprudencial, senão a seleção de algumas decisões que visam à análise da aplicação dos direitos da personalidade em âmbito laboral, mormente no que diz com a sua pertinência e suficiência no referido ambiente.

\subsection{Direito à honra}

Quanto ao direito à honra, vale referir que o Código Civil não o contempla em artigo específico, senão de forma indireta, no caput do artigo $20^{19}$, ao ditar que a divulgação de escritos, a transmissão da palavra, publicação, exposição ou utilização da imagem de alguém poderão ser proibidas, a seu requerimento, se lhe atingirem a honra. Além disso, o Diploma Civil não fez a importante distinção entre honra subjetiva e honra objetiva, cabendo, portanto, à doutrina fazê-lo. Nesse sentido, definiu-se a primeira como o conceito que o próprio sujeito tem de si; a segunda, à imagem ou reputação social que as pessoas fazem do indivíduo. Essa distinção tem relevante importância e pertinência no reconhecimento do direito da pessoa

18 Artigo $8^{\circ}$ [...] Parágrafo único - O direito comum será fonte subsidiária do direito do trabalho, naquilo em que não for incompatível com os princípios fundamentais deste.

19 Artigo 20. Salvo se autorizadas, ou se necessárias à administração da justiça ou à manutenção da ordem pública, a divulgação de escritos, a transmissão da palavra, ou a publicação, a exposição ou a utilização da imagem de uma pessoa poderão ser proibidas, a seu requerimento e sem prejuízo da indenização que couber, se lhe atingirem a honra, a boa fama ou a respeitabilidade, ou se se destinarem a fins comerciais. 
jurídica à reparação por dano extrapatrimonial em razão de violação à sua honra objetiva, matéria já sumulada pelo STJ. ${ }^{20}$

$\mathrm{Na}$ CLT, encontra-se, dentre as causas justificadoras da rescisão indireta (também chamada justa causa do empregador), a lesão à honra do obreiro ou de pessoas de sua família por ato praticado pelo empregador ou pelos seus prepostos ${ }^{21}$. Vê-se, no particular, a preocupação do legislador trabalhista com esta modalidade de direito da personalidade, fazendo-o de maneira plástica e imprecisa, permitindo a adequação do tipo jurídico a condutas tidas como notórias no ambiente laboral, como é o caso dos assédios moral e sexual.

É dizer, ainda que a CLT, em seu artigo 483, alínea “e”, elenque, genericamente, a prática de lesão à honra e boa-fama do empregado ou de pessoas de sua família como ato do empregador apto a gerar rescisão indireta do contrato de trabalho, em face da insuficiência da cláusula, pelo princípio da subsidiariedade, busca-se no Código Civil a complementação das suas hipóteses de incidência, que ainda não se fazem suficientes, por conta das peculiaridades do direito trabalhista. Neste caso, privilegia-se a operabilidade, entendida como um princípio norteador do Código Civil de 2002, para valorar o que vem a ser a lesão à honra do empregado, possibilitando-se o enquadramento dos assédios moral e sexual no tipo do artigo 483, alínea "e", da CLT.

Há, portanto, na jurisprudência trabalhista, um número expressivo de julgados condenando empregadores ao pagamento de indenização por danos morais aos seus obreiros, com fundamento na lesão ao direito à honra, em decorrência de assédio moral e sexual.

Marie-France Hirigoyen, importante autora que trata do tema, destaca que o assédio moral começa, no mais das vezes, pela inaceitação de uma diferença. Essa recusa se manifesta por um comportamento que se situa no limite da discriminação, porém mais sutil e, às vezes, quase imperceptível a todos os integrantes do grupo. São exemplos: propostas sexistas para desencorajar uma mulher a aceitar uma função tipicamente masculina, brincadeiras grosseiras em relação a um homossexual, bullying, etc. (HIRYGOYEN: 2015).

Quanto ao assédio sexual, outra causa de significativo número de condenações por danos morais na Justiça do Trabalho, define-se como a conduta de importunação reiterada e maliciosa, explícita ou não, com interesse e conotações sexuais, de uma pessoa física em relação a outra. Godinho destaca que a importância do tema, em face do novo status jurídico

\footnotetext{
${ }^{20}$ STJ. Súmula no 227 - 08/09/1999 - DJ 20.10.1999 - Pessoa Jurídica - Dano Moral. A pessoa jurídica pode sofrer dano moral

${ }^{21}$ CLT. Artigo 483 - O empregado poderá considerar rescindido o contrato e pleitear a devida indenização quando: [...] e) praticar o empregador ou seus prepostos, contra ele ou pessoas de sua família, ato lesivo da honra e boa fama;
} 
conferido aos direitos da personalidade da pessoa humana, desde a Constituição Federal de 1988, fez esse censurável comportamento ultrapassar o acanhado conceito de incontinência de conduta, caracterizando-se de forma mais ampla na modalidade de assédio sexual (DELGADO: 2013).

Além dessas questões, no que se refere à lesão da honra do empregado, merecem referência as condenações de empregadores por danos morais, em razão da inclusão do nome de obreiros em "listas sujas", que se constituem em relações, feitas às margens da lei, de nomes de trabalhadores que tenham participado de movimentos paredistas, ou situações similares, com o fim de obstaculizar a contratação destes por outras empresas ${ }^{22}$.

Demais contendas, porém, que tragam como pano de fundo a lesão à honra do empregado são mais escassas nos julgados dos tribunais do trabalho. A partir dos exemplos, todavia, constata-se que o direito à honra e sua consequente violação é causa ensejadora de justa causa da empresa, operacionalizando-se a rescisão indireta, com reflexo nas verbas rescisórias, além da indenização por danos morais, reconhecida pela jurisprudência de forma bastante evidente nos casos mais extremos, como os referidos anteriormente. Contudo, a plasticidade do conceito dá azo ao questionamento quanto à adequação e suficiência do regramento civil para todos os casos de lesão ao direito à honra do empregado.

\subsection{Direito à imagem e ao uso do nome}

$\mathrm{O}$ direito à imagem e o direito ao nome encontram-se positivados nos artigos $18^{23} \mathrm{e}$ 20 do Código Civil, plenamente aplicáveis em seara laboral. Isto é, apenas no caso de autorização do indivíduo ou, ainda, se necessário à administração da justiça ou à manutenção

22 AGRAVO DE INSTRUMENTO. RECURSO DE REVISTA. PROCESSO SOB A ÉGIDE DA LEI 13.015/2014. 1. INDENIZAÇÃO POR DANO MORAL. INCLUSÃO DO NOME DO RECLAMANTE EM "LISTA SUJA" DE TRABALHADORES. DESRESPEITO AOS PRINCÍPIOS FUNDAMENTAIS DA DIGNIDADE DA PESSOA HUMANA, DA INVIOLABILIDADE PSÍQUICA (ALÉM DA FÍSICA) DA PESSOA HUMANA, DO BEM-ESTAR INDIVIDUAL (ALÉM DO SOCIAL) DO SER HUMANO, TODOS INTEGRANTES DO PATRIMÔNIO MORAL DA PESSOA FÍSICA. DANO MORAL CARACTERIZADO. INCIDÊNCIA, ADEMAIS, DA SÚMULA 126/TST, RELATIVAMENTE AOS FATOS EXPLICITADOS NO ACÓRDÃO. A confecção e divulgação de listas de nomes de trabalhadores que tenham proposto ação judicial contra seus empregadores (ou que tenham participado de movimentos paredistas, a par de outras situações similares) têm sido compreendidas pela jurisprudência como conduta deflagradora de manifesto dano moral, seja com respeito a cada indivíduo presente na lista (dano moral individual ou até mesmo plúrimo), seja com respeito a toda a comunidade de trabalhadores (dano moral coletivo). É que tais listas sujas conteriam nítido intuito discriminatório, visando a potencial retaliação de seus componentes pelo mercado empresarial circundante - em conformidade com a compreensão da experiência advinda da observação das práticas sociais no cotidiano, tão bem inferida e sopesada por juízes e tribunais. Agravo de instrumento desprovido. Processo: AIRR - 10151-32.2014.5.03.0129 Data de Julgamento: 08/06/2016, Relator Ministro: Mauricio Godinho Delgado, $3^{\mathrm{a}}$ Turma, Data de Publicação: DEJT 10/06/2016.

${ }^{23}$ Artigo 18. Sem autorização, não se pode usar o nome alheio em propaganda comercial. 
da ordem pública, poderá ser publicada, exposta ou utilizada a imagem ou o nome de uma pessoa.

Quanto à autorização, questiona-se, a teor do artigo 111 do Código Civil ${ }^{24}$, se precisa ser expressa ou pode ser tácita. Impende referir que, em se tratando da cessão da imagem, o Superior Tribunal de Justiça - STJ tem posição, desde a década de 1990, que privilegia a aplicação restritiva do artigo 111, no sentido de que somente em posições muito claras e específicas pode ser aceito o consentimento tácito ${ }^{25}$.

Comumente, encontra-se na jurisprudência trabalhista julgados envolvendo a utilização do nome de empregados, por vezes após o rompimento da relação contratual, para fins comerciais. Assim, a empresa que visa a locupletar-se do nome ou da imagem do seu empregado, sem seu consentimento, deve-lhe indenização a título de danos morais, sem necessidade de comprovação do dano. ${ }^{26}$

No que se refere ao direito do trabalho, em razão da assimetria que envolve as partes envolvidas na relação de emprego, mormente por conta da hipossuficiência do empregado em contraposição ao poder econômico-diretivo do empregador, advoga-se por uma interpretação restritiva quanto à autorização da divulgação de imagens e do nome, isto é, somente com o consentimento expresso do empregado e, ainda assim, a depender do caso concreto considerando a presunção de necessidade do emprego e o caráter alimentar da verba trabalhista - desde que não fira a sua dignidade, será possível a utilização do nome do empregado para fins comerciais da empresa.

\subsection{Direito à privacidade}

\footnotetext{
${ }^{24}$ Artigo 111. O silêncio importa anuência, quando as circunstâncias ou os usos o autorizarem, e não for necessária a declaração de vontade expressa.

${ }^{25}$ DIREITO À IMAGEM. Direito de arena. Jogador de futebol. Álbum de figurinhas. O direito de arena que a lei atribui às entidades esportivas limita-se à fixação, transmissão e retransmissão do espetáculo desportivo público, mas não compreende o uso da imagem dos jogadores fora da situação específica do espetáculo, como na reprodução de fotografias para compor "álbum de figurinhas". Lei 5989/73, artigo 100; Lei 8672/93. (RESP 46420-0/SP. Data do julgamento 12/09/1994, Relator: Ministro Ruy Rosado de Aguiar).

${ }^{26}$ I - AGRAVO DE INSTRUMENTO EM RECURSO DE REVISTA. PROCEDIMENTO SUMARÍSSIMO. ACÓRDAO PUBLICADO SOB A ÉGIDE DA LEI No 13.015/14 - INDENIZAÇÃO POR DANO MORAL. USO INDEVIDO DO NOME DO RECLAMANTE APÓS O TÉRMINO DA RELAÇÃO DE EMPREGO. Constatada a violação do art. $5^{\circ}, \mathrm{X}$, da Constituição Federal, impõe-se o provimento do agravo de instrumento a fim de determinar o processamento do recurso de revista. II - RECURSO DE REVISTA - INDENIZAÇÃO POR DANO MORAL. USO INDEVIDO DO NOME DO RECLAMANTE APÓS O TÉRMINO DA RELAÇÃO DE EMPREGO. O uso indevido do nome do empregado após o término da relação empregatícia, sem a sua autorização, configura abuso do poder diretivo do empregador, a justificar sua condenação ao pagamento de indenização por danos morais. Recurso de revista conhecido e provido. (TSR- RR- 67304.2014.5.20.0007).
} 
O Código Civil, em seu artigo 21, prevê a inviolabilidade da vida privada da pessoa natural, cabendo ao juiz, a requerimento do interessado, adotar as providências necessárias para impedir ou fazer cessar o ato violador. Constata-se, pois, que o diploma civil não faz uso da terminologia "privacidade" e sim da "vida privada".

No Brasil, a doutrina utiliza-se de variadas terminologias para referir-se à "privacidade", dentre as quais são mais comumente encontradas as expressões vida privada, intimidade, intimidade da vida privada, sigilo, segredo ou recato. E tal profusão de termos doutrinários, em determinada medida, é compreensível, pois nada mais faz do que refletir a dificuldade de identificação de contornos específicos para esse direito, que se coloca, nas palavras de Danilo Doneda, como um componente essencial da formação da pessoa. (DONEDA: 2011)

José Afonso da Silva prefere usar a expressão “direito à privacidade”, em sentido amplo e genérico, abarcando, em um só conceito, as manifestações da esfera íntima e da privacidade trazidas pelo artigo $5^{\circ}, \mathrm{X}$, da Constituição Federal. Para o autor, assim como para J. Matos Pereira e Moacyr de Oliveira, a privacidade é um conjunto de informações mantidas pelo indivíduo exclusivamente sob seu controle, ou compartilhadas, por decisão sua, a quem e onde lhe aprouver. A esfera da inviolabilidade da privacidade, portanto, seria ampla, abrangendo o modo de vida doméstico, relações familiares, afetivas, fatos, hábitos, local, nome, imagem, pensamentos, segredos, origens e planos. (SILVA: 2016)

Com efeito, sendo ampla a esfera de inviolabilidade da privacidade do indivíduo, há de ser reconhecido que, mesmo no ambiente laboral, ainda que com temperamentos, em razão do poder diretivo do empregador, o empregado deve ter preservada a sua privacidade.

Fábio Siebeneichler de Andrade destaca que a disciplina da privacidade no diploma civil é praticamente ociosa, na medida em que não define, suficientemente, os diversos aspectos dessa temática. Ressalta, ainda, que no Direito Europeu houve expresso reconhecimento, no caso Niemietz contra a Alemanha, julgado pela Corte Europeia de Direitos Humanos, em dezembro de 1992, de que o conceito de vida privada abrange, também, o ambiente laboral. (ANDRADE: 2009)

Outro fator importante no que diz respeito à privacidade nos ambientes corporativos, é a adoção de novas ferramentas tecnológicas que, além de aprimorar e facilitar a comunicação, aumentam sobremaneira a vigilância dos empregadores sobre os empregados, importando, em algumas situações, em restrição e limitação do direito fundamental à privacidade. 
Questão polêmica relativa ao tema já foi apreciada pelo Tribunal Superior do Trabalho - TST, no Recurso de Revista n. 61300-23.2000.5.10.0013, de relatoria do Ministro João Oreste Dalazen, que tratava da inviolabilidade do e-mail corporativo. Na oportunidade, o TST decidiu que é possível ao empregador, por ser o detentor das ferramentas tecnológicas colocadas à disposição do empregado, bem como do provedor que the dá acesso, o monitoramento geral e irrestrito do seu conteúdo. Essa posição, apesar de criticada por parte da doutrina, segue predominante nos tribunais trabalhistas.

Além das situações relativas à comunicação entre os empregados, outra questão que envolve a privacidade do trabalhador no ambiente laboral, frequentemente levada a Juízo, refere-se às revistas íntimas em empregados. Destaca-se que a própria CLT, em seu artigo $373-\mathrm{A}^{27}$, no capítulo destinado à proteção do trabalho da mulher - mas que se aplica a todos os trabalhadores - veda ao empregador ou preposto proceder a revistas íntimas nas empregadas ou funcionárias. Porém, é prática comum a revista pessoal, em objetos como sacolas, bolsas e outros pertences. A posição predominante na jurisprudência é no sentido de que tais revistas são toleráveis, desde que não afetem a dignidade do trabalhador. Nesse sentido, tem sido aceita pela jurisprudência a revista pessoal, com prévia e adequada divulgação, mediante procedimentos objetivos, mesmo que sem a concordância do empregado. $^{28}$

No caso das revistas pessoais, tidas como aceitas, via de regra, pela jurisprudência trabalhista, é possível extrair a existência de dois interesses em conflito: de um lado, o direito de propriedade do empregador, bem como o seu poder diretivo; de outro, o direito fundamental do empregado à privacidade e à intimidade. Na hipótese, entende-se que se faz mister sopesar se a medida é, efetivamente, necessária, adequada e proporcional, sob pena de ferimento da dignidade humana do empregado. Ou seja, advoga-se, como se tem feito ao

27 Artigo 373-A. Ressalvadas as disposições legais destinadas a corrigir as distorções que afetam o acesso da mulher ao mercado de trabalho e certas especificidades estabelecidas nos acordos trabalhistas, é vedado: (Incluído pela Lei $\mathrm{n}^{\circ}$ 9.799, de 26.5.1999)

$[\ldots]$

VI - proceder o empregador ou preposto a revistas íntimas nas empregadas ou funcionárias. (Incluído pela Lei $\mathrm{n}^{\mathrm{0}}$ 9.799, de 26.5.1999)

28 “RECURSO DE REVISTA - INDENIZAÇÃO - DANO MORAL - REVISTA VISUAL DO EMPREGADO E DE BOLSAS E SACOLAS - AUSÊNCIA DE CONTATO FÍSICO. A revista apenas visual do empregado e de bolsas e sacolas dos funcionários da empresa, realizada de modo impessoal, geral, sem contato físico e sem expor a intimidade do obreiro, não submete o trabalhador à situação vexatória e não abala o princípio da presunção da boa-fé que rege as relações de trabalho. O ato de revista do funcionário e de bolsas e sacolas, por meio de verificação meramente visual, é lícito e consiste em prerrogativa do empregador inserida dentro do seu poder diretivo, não caracterizando prática excessiva de fiscalização capaz de atentar contra os direitos da personalidade do empregado, em especial sua dignidade e intimidade. Recurso de revista não conhecido". (Proc.: RR - 86700-12.2008.5.09.0005. Data de Julgamento: 08/02/2012, Relator Min. Luiz

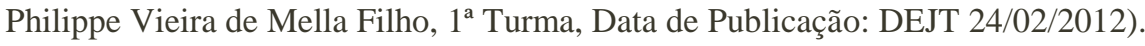


longo deste estudo, por uma posição restritiva, no sentido de que somente em casos muito específicos e, portanto, excepcionais, que não permitam meio menos invasivo, podem os empregadores fazer uso da revista pessoal, de modo a privilegiar a preservação dos direitos da personalidade do trabalhador, dando-se concretude à dignidade da pessoa humana.

\section{CONSIDERAÇÕES FINAIS}

Pretendeu-se apresentar alguns pontos do universo temático dos direitos da personalidade do trabalhador. Inicialmente, expôs-se uma breve narrativa acerca do desenvolvimento dos direitos da personalidade, seu conceito, natureza jurídica e características. Posteriormente, objetivou-se instigar a reflexão sobre a suficiência e adequação da legislação cível, no que se refere à proteção dos direitos da personalidade do trabalhador.

Evidentemente, ante o propósito desta pesquisa, não foi possível a análise de um número mais expressivo de julgados e demandas levadas à apreciação do Judiciário relativamente à temática da ofensa aos direitos da personalidade do trabalhador. Todavia, acredita-se que as breves referências feitas são suficientes para que se perceba a posição conservadora e refratária da jurisprudência trabalhista no que tange à proteção mais efetiva desses direitos.

Com efeito, salta aos olhos a assimetria existente na relação empregado-empregador e, sob o argumento do poder diretivo, muitas vezes, percebe-se que os direitos da personalidade do empregado são lesados ou insuficientemente protegidos. Pode-se exemplificar a afirmativa com o problema das revistas íntimas, até pouco tempo realizadas de maneira corriqueira pelas empresas e, ainda hoje, as revistas pessoais, na maioria das vezes operacionalizadas sem que se verifique absoluta necessidade para tal.

É dizer, ainda no contexto das revistas pessoais e sua adequação ou necessidade, advoga-se que tais medidas, a despeito de serem consideradas legais em determinadas situações, devem ser tomadas em casos muito específicos, quando não houver meio menos invasivo para fazê-las, de forma a não ofender a dignidade do trabalhador. A análise jurisprudencial, todavia, demonstra o contrário: o uso indiscriminado das revistas pessoais, no mais das vezes, consideradas legais e, apenas em casos excepcionais, reconhecidas como indevidas. 
Ademais, o direito de propriedade do empregador, revelado no seu poder diretivo, não pode salvaguardar a invasão desmesurada e generalizada a direito de personalidade do empregado que, subjugado ao superior hierárquico, cumpre com desideratos de duvidosa constitucionalidade.

Por fim, salienta-se que o poder diretivo do empregador, fundado na propriedade dos meios de produção, admite temperamentos, porquanto é dele o ônus de arcar com os riscos do negócio, não podendo ultrapassar a barreira da dignidade da pessoa humana para resguardarse de qualquer prejuízo financeiro.

De tudo quanto foi exposto, portanto, percebe-se que a atual legislação civil, aplicada com amparo no artigo $8^{\circ}$ da CLT, não protege de forma adequada e suficiente os direitos da personalidade do empregado, que ainda está, em razão de uma forte assimetria, em posição extremamente desvantajosa em relação ao empregador.

\section{REFERENCIAS BIBLIOGRÁFICAS}

ALVES. José Carlos Moreira. A parte Geral do Projeto de Código Civil Brasileiro. $2^{\mathrm{a}}$ ed. São Paulo: Saraiva, 2003.

ANDRADE, Fábio Siebeneichler de. A tutela dos direitos da personalidade no direito brasileiro em perspectiva atual. In Revista de Derecho Privado, 2013.

Considerações sobre o desenvolvimento dos direitos da personalidade e sua aplicação às relações de trabalho. In Direitos Fundamentais e Justiça. Porto Alegre, v. 3, n. 6, p. 162-176, 2009.

BITTAR, Carlos Alberto. Os direitos da personalidade. $5^{\text {a }}$ ed. Rio de Janeiro: Forense Universitária. 2001.

BRASIL, Código Civil, de 10 de janeiro de 2002.

. Consolidação das leis do trabalho, de $1^{\circ}$ de maio de 1943.

. Constituição Federal, de 05 de outubro de 1988.

CANTALI, Fernanda Borghetti. Direitos da personalidade: disponibilidade relativa, autonomia privada e dignidade humana. Dissertação de mestrado, 2008.

DALLEGRAVE NETO, José Affonso; Günther, Luiz Eduardo (coord.). O Impacto do Novo Código Civil no Direito do Trabalho. São Paulo: Ltr, 2003.

DELGADO, Maurício Godinho. Curso de Direito do Trabalho. São Paulo: Editora LTR, 2013.

DONEDA, Danilo. A proteção dos dados pessoais como um direito fundamental. Espaço Jurídico: Journal of Law, v. 12, n. 2, p. 91-108, Dez. 2011. Disponível em: 
http://editora.unoesc.edu.br/index.php/espacojuridico/article/view/1315/658. Acesso em 29 de maio de 2016.

A tutela da privacidade no código civil de 2002. p. 1. Disponível em: http://www.animaopet.com.br/primeira_edicao/artigo_Danilo_Doneda_a_tutela.pdf Acesso em 29 de maio de 2016.

. Da Privacidade à Proteção de Dados Pessoais. Rio de Janeiro: Renovar, 2006.

GAGLIANO, Pablo Stolze; PAMPLONA FILHO, Rodolfo. Novo Curso de Direito Civil. $11^{\text {a }}$ ed. São Paulo: Saraiva, 2009.

HIRIGOYEN, Marie-France. Assédio moral. A violência preserva do cotidiano (tradução: Maria Helena Kühner). 15.ed. Rio de Janeiro: Bertrand Brasil, 2014.

Mal-estar no trabalho. Redefinindo o assédio moral (tradução: Rejane Janowitzer). 8.ed. Rio de Janeiro: Bertrand Brasil, 2015.

LOBO, Paulo. Direito Civil. Parte Geral. $4^{\mathrm{a}}$ ed. São Paulo: Saraiva, 2013.

MIRANDA, Jorge; RODRIGUES JÚNIO, Otávio Luiz; FRUET, Gustavo Bonato (coord.). Direitos da Personalidade. São Paulo: Atlas, 2012.

MONTEIRO, Whashington de Barros; PINTO, Ana Cristina de Barros Monteiro França. Curso de Direito Civil. $44^{\text {a }}$ ed. São Paulo: Saraiva, 2012.

PAMPLONA FILHO, Rodolfo. O dano moral na relação de emprego. São Paulo: Ltr, 1998.

RUARO, Regina Linden e RODRIGUEZ, Daniel Piñeiro. O direito à proteção de dados pessoais na sociedade da informação. p. 9. Disponível em: http://direitoestadosociedade.jur.pucrio.br/media/8ruaro_rodriguez36.pdf. Acesso em: 29 de maio de 2016.

RUARO, Regina Linden, RODRIGUEZ, Daniel Piñeiro e FINGER, Brunize (Colaboradora). O direito à proteção de dados pessoais $\mathbf{e}$ a privacidade. p. 7 . Disponível em: http://www.egov.ufsc.br/portal/sites/default/files/o_direito_a_protecao_de_dados_pessoais_ e_a_privacidade_0.pdf. Acesso em 29 de maio de 2016.

SARLET, Ingo Wolfgang. A eficácia dos direitos fundamentais. Uma teoria geral dos direitos fundamentais na perspectiva constitucional. 12.ed. Porto Alegre: Livraria do Advogado, 2015,

Dignidade da pessoa humana e direitos fundamentais na Constituição Federal de 1988. 9.ed. Porto Alegre: Livraria do Advogado, 2012.

SCHREIBER, Anderson. Direitos da personalidade. 2.ed. São Paulo: Atlas, 2013.

TEPEDINO, Gustavo. A tutela da personalidade no ordenamento civil-constitucional brasileiro. In Temas de Direito Civil. $2^{\mathrm{a}}$ ed. Rio de Janeiro: Renovar, 2001.

VIEIRA, Tatiana Malta. $O$ direito à privacidade na sociedade da informação: efetividade desse direito fundamental diante dos avanços da tecnologia da informação. Porto Alegre: Fabris, 2007.

WARREN e BRANDEIS. The right to privacy. Harvard law review. Disponível em: http://groups.csail.mit.edu/mac/classes/6.805/articles/privacy/Privacy_brand_warr2.html. Acesso em 29 de maio de 2016. 